\title{
Cidades (in)habituais: considerações sobre neoliberalismo e resistência
}

\author{
Fernanda Spanier Amador „ Daniel Rodrigues Fernandes \\ Universidade Federal do Rio Grande do Sul, Porto Alegre, RS, Brasil
}

\section{Resumo}

Este texto discute os efeitos do neoliberalismo nos modos de vida urbanos, traçando elementos que permitam experimentar e estranhar a cidade para, assim, resistir à lógica econômica e aos arranjos subjetivos arrimados nos fios do Capitalismo Mundial Integrado. Duas cenas urbanas são apresentadas: em uma delas, tematiza-se a situação que envolve um serviço localizado em uma grande cidade brasileira que acolhe usuários de drogas, em outra, aborda-se uma situação que envolve um morador de rua. São discutidos os códigos capitalísticos que esquadrinham as cidades visando a instauração de resistência às estratégias de capitalização subjetiva e gerando, assim, cidades (in)habituais.

Palavras-chave: cidades; neoliberalismo; resistência.

\section{(Un)habitual cities: considerations on neoliberalism and resistance}

\begin{abstract}
This paper discusses the effects of neoliberalism in urban ways of life, tracing elements to experiment and defamiliarize the city in order to resist the economic logic and the subjective arrangements supported on the Integrated World Capitalism wires. Two urban scenes are presented: one of them accounts the situation of a service aimed at drug users that is rejected by the local population in a large Brazilian city. The capitalistic codes that overcodify the cities are discussed, with the aim to establish creative relations on the space of the cities, relations that are able to resist the subjective capitalizing strategies and, thus, to seed unusual (unhabitual) cities.
\end{abstract}

Keywords: cities; neoliberalism; resistance.

Este texto discute os efeitos do neoliberalismo nos modos de vida urbanos, traçando elementos que permitam experimentar e estranhar a cidade para, assim, resistir à lógica econômica e aos arranjos subjetivos arrimados nos fios do Capitalismo Mundial Integrado (CMI) que se engendram nas chamadas Cidades Globais.

Por CMI entendemos, na esteira do pensamento de Guattari (GUATTARI; ROLNIK, 1996), a modalidade de configuração do capitalismo contemporâneo, assumida, especialmente, a partir das três últimas décadas do século XX. Trata-se de um modo de produção que incorpora à produção de subjetividade, todos os tipos de atividades que formalmente escapavam da definição clássica de trabalho, o fazendo de uma maneira como nunca antes se viu na história. Partindo da ideia de que tal modalidade se sustenta por um intenso e constante processo de capitalização subjetiva, com esta definição o autor coloca em cena aquilo que define como produção desejante dos indivíduos na direção de sua captura pelos valores de mercado.

Pensando a cidade enquanto espaço geográfico-existencial, a problematizamos enquanto zona de habit(ação) na qual seus agentes são dotados de capacidade inventiva, algo como sugere Bourdieu (1983, p. 65) com o conceito de habitus pelo qual se refere a um "[...] sistema de disposições duráveis e transponíveis que, integrando todas as experiências passadas, funciona a cada momento como uma matriz de percepções, de apreciações e de ações - e torna possível a realização de tarefas infinitamente diferenciadas, graças às transferências analógicas de esquema”.

\footnotetext{
* Endereço para correspondência: Universidade Federal do Rio Grande do Sul, Instituto de Psicologia. Ramiro Barcelos, 2600 - Santana, Porto Alegre, RS Brasil.CEP: 90035003.E-mail: feamador@uol.com.br,drf.daniel@gmail.com
}

Nessa direção, porém, por nuances diferenciais, buscamos inspiração, também, nas considerações de Do Eirado (1998) a respeito do hábito, pelas quais o autor segue uma linha argumentativa de que o habitual não é resposta às situações e sim, problemas que formam ou constroem as situações onde vão operar. Com isso, o autor nos ajuda a pensar por uma espécie de revés do hábito, por uma dimensão (in)habitual responsável por sua transformação e que, quando pensada no escopo da cidade enquanto território a habitar, se oferece como caminho para a instauração de relações criadoras na esfera do espaço urbano.

Criação, problematização e práticas de resistência em uma sociedade de consumo desenfreado cujas lógicas sustentam um ideário de cidade a con(sumir), na qual a liberdade é pensada em termos de possibilidade de acesso a bens e serviços e não enquanto direito de mudar a cidade, para usar as palavras de Harvey (2013a), ou ainda, como direito à vida, como diz Lefebvre (1991). Mudar a cidade que aqui pensamos enquanto prática de resistência ativa, isto é, enquanto relação problematizadora do jogo do verdadeiro e do falso no que tange à vida na urbe, enquanto afirmação de um ethos que, como sugere Foucault (2005), nos permite um embate com as artes de governar. Uma resistência feita da geração de territórios e existências (in)habituais.

\section{As Cidades Globais do Neoliberalismo}

$\mathrm{O}$ interesse pela cidade tem marcado, particularmente, esse início de século, especialmente pela constatação de que as cidades são os locais centrais de administração e controle do capitalismo global contemporâneo (ALSAYYAD; ROY, 2009). 
Com inspiração no neoliberalismo norte americano, o qual se opõe à afirmação do Estado como agente indispensável de controle da economia e vinculado a uma noção de bem-estar social, os arranjos sociais, particularmente na esfera das cidades, expressam a proliferação dos sujeitos economicamente ativos, aqueles que no rastro de uma concepção atomística do indivíduo investem-se como empresários de si mesmos, fazendo ruir as bases para o estabelecimento de solidariedades.

O trabalho, agora reposicionado na análise econômica, não mais tomado como instância operada entre capital e produção e sim enquanto conduta econômica praticada, gera trabalhadores que habitam a cidade e que produzem um modo de habitá-la, fazendo-se, eles próprios, seu capital, sendo para si mesmos seus produtores, sendo para si mesmos a fonte de sua renda, como sugere Foucault (2008a). Renda que os coloca na posição tão almejada de se constituírem como consumidores de bens, de serviços, de modos de existência, de cidade, de modo útil à perpetuação do fluxo de produção do capital. A emergência desse homo oeconomicus (FOUCAULT, 2008a) revela, assim, a torção histórica que vai do trabalhador como homem de troca para o trabalhador como homem consumidor (LAZZARATO, 2006).

Os habitantes da cidade passam, então, a relacionar-se uns com os outros como a encarnação das funções econômicas que ocupam. Suas existências passam a ser colonizadas por este aspecto. Essa organização social fora já vaticinada por Huxley (2004[1932]), quando este autor revisita seu Admirável mundo novo no final da década de 50 e avalia que estivera perigosamente certo em suas previsões. As leis de competição pontuadas pelo ideal econômico do neoliberalismo atravessam nossa sociedade de modo sistêmico, forçando todos a, em diferentes níveis, encaixar-se na forma de um sistema cruel e insensível (HARVEY, 2012).

O neoliberalismo, então, enquanto teoria das práticas político-econômicas, propõe que o bem-estar humano pode ser melhor promovido liberando-se as liberdades e capacidades empreendedoras individuais no âmbito de uma estrutura institucional caracterizada por sólidos direitos à propriedade privada, livres mercados e livre comércio, diz Harvey (2013b). É nesse rastro, portanto, que determinadas racionalidades acerca da vida na cidade sustentam que o direito a ela consiste na liberdade e na possibilidade de acesso a tudo aquilo que um acelerado e frenético crescimento econômico pode oferecer, ainda que estejamos cada vez mais aprisionados nas circunscrições de formato e de limites espaciais que produzem distâncias a serem mantidas por fortes esquemas de segurança, vigilância e controle. Assiste-se à fragmentação do público e ao enfraquecimento de um coletivo viável acenando-se com o direito virtual à propriedade enquanto via, paradoxal, para o exercício da liberdade na urbe.

Cidades globais, paradoxalmente, interconectadas e apartadas, recheadas de estilhaços desiguais que instauram no espaço urbano disputas e debates relativos à garantia de direitos, os quais, na maioria das vezes, restringem-se ao direito de ir e vir, de acessar, de consumir ao invés de primar pelo direito de diferir. Cidades Globais, porém, recheadas de esquadrinhamentos privados e individualizados em expressões, muitas vezes, máximas, de fratura dos coletivos e de enfraquecimento do direito de singularizar.

Estão na tônica dos interesses neoliberais as interferências das lógicas de mercado sobre a vida na e da cidade, expressas na transferência de espaços públicos para a exploração de lucros privados, bem como nas delimitações territoriais e subjetivas características dos shoppings e dos condomínios fechados. Todos esses lugares disciplinados e, portanto, imediatamente vinculados a estratégias de segurança, como adverte Foucault (2008b). Criam-se espaços exclusivos a alguns em detrimento de outros e propõem-se políticas de remoção dos pobres dos centros urbanos e dos espaços dotados de valorização pela especulação imobiliária, sendo eles lançados para regiões inóspitas, sem condições mínimas de sobrevivência em condições dignas. Crescem, também, as práticas que criminalizam em nome do desenvolvimento urbano, expressando a privatização das cidades, segundo Alsayyad e Roy (2009), e valendo-se, para tanto, de técnicas sofisticadas de vigilância, policiamento e arquitetura. Trata-se de técnicas pautadas em interesses privados aliadas a políticas de remoção dos pobres das cidades, de criminalização dos despossuídos em nome do desenvolvimento urbano, bem como de cercamento dos espaços em megaprojetos urbanos nos quais a "ética da propriedade é o fundamento da vida comunitária e a exclusão é o fundamento da organização social" (ALSAYYAD; ROY, p. 112).

Verdadeiras práticas de segregação espacial, que Low, citado por Alsayyad e Roy (2009), chama de nova estrutura espacial de governo, cuja principal característica desses regimes é a formação de conjuntos cercados governados por entes privados, tal como nos condomínios habitacionais, ou, então, a criação de legiões de expulsos dos centros urbanos, lançados às periferias sem sequer vigilância, exceto quando passam a constituir ameaça, o que coloca instigantes questões no que se refere às tecnologias de subjetivação, soberania e espacialidade.

É assim que o discurso em torno da noção de liberdade e do poder tende a se amalgamar de um modo muito peculiar no que tange ao tema da cidade na contemporaneidade: algo que Rose (1999) denomina de "poderes da liberdade", essas formas de governar enquanto pressuposto da liberdade dos governados.

Geram-se "cidades-controladas", fazendo subsumir, muitas vezes, as "cidades-devires-revolucionários" que por entre elas se esgueiram, sendo as primeiras afeitas a práticas higienistas e aprisionantes em nome da necessidade de combater a insegurança urbana enquanto as segundas, articulam direito, cidade e humanidade como diferentes expressões de um mesmo processo, a saber: uma ética ou um modo de viver que tem como ponto de partida a experiência da diferença (LAGES, 2013).

Em tais cidades, vê-se crescer uma espécie de política penal que se encarrega de difundir ideários de ordem por onde o público pode ganhar ares de ameaçador, en- 
quanto o privado é revestido de conceitos de segurança e confiabilidade. Estabelece-se um domínio de uma lógica individualista onde o outro é alienado de suas relações, convívios ou preocupações. Cria-se "um exterior supostamente ameaçador, hipertrofiado pelo medo e insegurança, associado ao individualismo exacerbado, que passa a produzir atitudes egocêntricas, como a indiferença ou a intolerância ao outro, a desconfiança e o isolamento" (JORGE, 2009, p. 263).

A vida coletiva das cidades é sobrepujada pelo domínio do privado. No paradigma da política penal da sociedade de controle, o que cabe é viver a administração dos riscos enquanto balizador para o controle dos outros. Uma micropolítica da insegurança, atualizada na microgestão de pequenos medos, sustenta a organização de uma grande "segurança" molar (DELEUZE; GUATTARI, 1996).

Hardt e Negri (2014) tratam desta figura oprimida pelo medo e sequiosa de proteção construída pelo regime de segurança - o securitizado. Para estes autores, em uma sociedade securitizada há um duplo papel a ser cumprido: simultaneamente, se é vigia e vigiado, presidiário e guarda. O habitante da cidade é objeto e sujeito de uma máquina de segurança aparentemente universal. Um medo social generalizado está instalado, abarcando desde as possibilidades de punição dos poderes dominantes até o risco de perder as poucas garantias que se pode encontrar nessa ordem (ficar desempregado, e, portanto, sem lugar na estrutura social pautada pelo lugar de produção), passando pelo medo do desconhecido que pode vir de qualquer lugar. "No regime de segurança, o medo é um significante vazio, no qual todos os tipos de fantasmas amedrontadores podem aparecer" (HARDT; NEGRI, 2014, p. 39).

É assim que se cria um imaginário de que a violência está nas ruas e de que a cidade necessita ser constantemente regulada e vigiada. Já nos espaços privados estaria a proteção, cada vez mais garantida por altos investimentos em sistemas de segurança privados. Vivemos tempos de cidades-controladas típicas da Sociedade de Controle, a qual para Passetti (2013) é muito ágil, quase não dando tempo às resistências para se organizarem e materializarem prolongadamente. A sociedade de controle é uma sociedade de velocidade muito grande onde as resistências são rapidamente capturadas, diz ele. Sendo assim, podemos nos perguntar a respeito de como produzir resistência na e pela cidade? Como fomentar e de onde extrair um resto de forças políticas capazes de enfrentar, por exemplo, os discursos que tendem a decalcar o tema da mobilidade urbana com a possibilidade de deslocamento no plano extensivo das cidades quando a questão-chave remete, sobretudo, ao seu plano intensivo, isto é, aos movimentos que podem ganhar as cidades no sentido de combater seus esquadrinhamentos e institucionalizações mediante a afirmação de novos e criativos usos dos espaços urbanos? Como combater a racionalidade que amalgama direito à cidade com direito à moradia, essa geralmente assegurada por precários financiamentos imobiliários que segregam uma parcela significativa da população nas periferias das cidades? Como enfrentar a produção de um ideário de que a cidade é lugar de ameaça, quando considerada em relação ao espaço privado, afirmando-a, ao invés disso, enquanto lugar de produção de vida e de coletivos?

Assim perguntamos, porque nas cidades globais não estamos apenas encarcerados nos ambientes fechados, temos o espaço público também como alvo de uma espécie de encarceramento quando são atacados em sua potência de emergência das coletividades. Isto nos leva a crer, juntamente com Lages (2013, p. 121), que a luta pelo direito à cidade não pode ser resumida aos objetivos e direitos individuais de ordem prática, tais como moradia e transporte, mas precisa "colocar em evidência uma dimensão aberta e experimental da vida", dimensão essa característica de uma experiência do comum, de abertura ao Outro, de acolhimento à multiplicidade e que produz um funcionamento difícil de capturar (BARROS; PIMENTEL, 2012).

Sustentando que a liberdade de fazer e refazer a nós mesmos e as nossas cidades é um dos mais preciosos de todos os direitos humanos, Harvey (2013a) nos inspira a pensar que é por nossas práticas cotidianas que as arquitetamos, em uma espécie de obra inacabada, por entre nossas experiências feitas, em nosso ponto de vista, de um tanto de hábito mas também e, sobretudo, de potentes porções de estranhamentos oriundos daquilo que podemos chamar de (in)habitual.

Assim, esse é o desafio: como estranhar a cidade de modo a produzir rupturas nos sentidos cristalizados sobre ela e sobre nós mesmos? Como conectar-se com a diversidade reconhecendo que o direito à cidade não pode ser concebido como um direito individual, que ele demanda um esforço coletivo? Como fazê-lo frente a tantos dispositivos de captura privatizantes? Como expandir o poder de agir e, como sugere Harvey (2013a), os direitos além do confinamento estreito ao qual o neoliberalismo o reduz? Como, enfim, mais do que defender o espaço urbano, afirmar a vida urbana?

\section{Por entre Cidades Habituadas, Cidades (in)habituais}

Tomemos uma vivência urbana. Um serviço que acolhe usuários de drogas localizado em uma grande cidade brasileira. Trata-se de um serviço visto com desconfiança e que goza de precárias condições. Eis que é noticiado que este mesmo serviço se mudará, passando a ocupar um espaço com uma infraestrutura mais adequada, em um local de mais fácil acesso. Essa notícia, ao invés de ser recebida pelos atendidos pelo serviço com alegria, gera desconforto e certo medo. Este novo espaço está localizado em um bairro que, a princípio, não acolheria tal população o que se confirma pelo fato de que os moradores já lá estabelecidos, fazem um abaixo-assinado tentando impedir que este dispositivo de acolhimento lá se instale. A circulação dessas pessoas (os acolhidos em um serviço de atenção a usuários de drogas) na localidade ampliaria a imagem de insegurança e baixaria o valor das propriedades, alegam alguns.

Pelos moradores, medo da insegurança trazida por estes "desconhecidos", receio de uma suposta desvalorização dos imóveis e do valor comercial da região. De parte dos acolhidos pelo serviço, medo de serem rechaça- 
dos pela população local. Vê-se aqui algo do que Razac (2013) conclama quando fala de uma "sociologia do arame farpado". Uma necessidade exacerbada de repartir os corpos no espaço, evitando o intolerável contato.

A cidade, que poderia ser espaço de acolhida à diferença, de possibilidade do outro, da alteridade, mostra-se fechada a ele. O outro, aqui, é um perigo em potencial: não um outro disponível ao encontro, mas "um outro a ser evitado". O outro é, aqui, um outro a ser temido. E, conforme sinalizam Hardt e Negri (2014), todo tipo de injustiça pode ser justificado pela aparição fantasmagórica deste medo generalizado.

Estamos ante outra cena urbana: um transeunte circula pela rua em um dia de chuva, portando um guarda-chuva que lhe protege da precipitação. Em uma parada rápida, vai a uma padaria. Quando sai, o guarda-chuva não é encontrado à porta, local no qual, instantes atrás, o deixara.

Entra um novo personagem em cena. Protegendo-se da torrente d'água, outro habitante da cidade encontra-se abaixo da marquise. Veste-se com sacos de lixo, e parece ser um dos tantos que dormem na rua. $\mathrm{O}$ primeiro personagem pergunta ao segundo se este vira um guarda-chuva ali e, no silêncio que se segue, uma mensagem fácil se insinua. Por hora, porém, não comunica nenhuma verdade necessária.

Uma funcionária da padaria sai do estabelecimento com uma sacola de pães do dia anterior e a entrega para o morador de rua. Este aceita a doação e prepara-se para deixar a cena. Eis que, então, a funcionária constata (mais que pergunta) ao primeiro transeunte, que este havia ali chegado com um guarda-chuva. O morador de rua tem certa dificuldade em caminhar, demonstrando que a capa improvisada de sacos de lixo esconde algo. A mensagem que antes relutara em ser recebida irrompe neste momento alterando os lugares que cada personagem ocupa.

A funcionária o acusa e chama a atenção do morador de rua (agora, ocupando o lugar de ladrão), que retira o guarda-chuva subtraído e devolve-o ao seu dono original (agora, talvez, um cliente pagante lesado em seu direito à propriedade). A funcionária talvez seja, nesse momento, um instrumento de justiça ou minimamente a restauradora da ordem. O morador de rua convertido em ladrão quebra o acordo de ser um "bom" morador de rua - aquele que diariamente esperava do lado de fora da padaria (de modo a não incomodar os clientes pagantes) para receber a doação dos pães não consumidos no dia anterior. Ainda mudo, este se retira de cabeça baixa e segue seu caminho.

Duas cenas corriqueiras e cotidianas, principalmente nas grandes cidades. Cenas que para Caldeira (2000) expressam a intimidade entre violência e segregação no espaço urbano, pela qual erguem-se muros afetivos e de concreto, privatizam-se os espaços físicos e emocionais, gerando um olhar desconfiado em relação àquele que difere de mim. Cenas habituais, poderíamos dizer. Aquelas que por repetição, geram certa familiaridade, sem, contudo, deixarem de vir acompanhadas de seu revés: a potência de seu estranhamento.

Fractal, Rev. Psicol., v. 28 - n. 2, p. 252-256, 2016
Para Do Eirado (1998), os hábitos são vetor de produção de subjetividade, trata-se de problemas que formam ou constroem as situações mesmas em que vão operar. Assim, o hábito consiste em uma produção inconsciente de si. Desviando de uma leitura produzida pela psicologia da aprendizagem, pela qual acabamos por considerar o hábito como aquisição de comportamento automático, mecânico, resultado de condicionamentos e resultado do estabelecimento de uma série de conexões regulares entre estímulos e respostas, o hábito porta em si mesmo, uma fagulha de (in)adaptação.

É nesta (in)adaptação, neste (in)habitual que, nos parece, residem as possibilidades de resistência. Uma resistência tramada na recusa às leituras privatizantes que nos apartam uns dos outros, em uma expressão máxima da fratura da vida coletiva na urbe. Resistência que se faz por entre tornar sensível em nós alguma coisa que vamos acreditando que não nos pertence e não nos diz respeito. Trata-se de apostar em uma luta que produz multidão, conforme sugerem Hardt e Negri (2006), para fazer frente aos esquadrinhamentos de toda ordem, econômicos, sociais, tecnológicos, afetivos.

Eis um caminho para potencializar corpos intensivos que circulando pela cidade aumentem seu coeficiente de afetação permitindo a reinvenção das subjetividades já anestesiadas. Corpos que escapem dos arrimos que amalgamam sujeito drogado-pobre-ladrão e os vinculam a uma ameaça às populações. Corpos solidários capazes de nos possibilitar a crítica de nós mesmos neste processo.

Em um tempo marcado pela velocidade contemporânea de produção de capital em fluxo, a qual transforma o espaço urbano em lugar de passagem para o rápido refúgio nos esquadrinhamentos privados, supostamente dotados de segurança, as táticas de resistência parecem requerer estratégias de ocupação da cidade capazes de implodir com os limites de segregação que marcam nosso tempo. O desafio parece ser o de operar pela diferença de modo a combater a desigualdade. Há que se apostar em devires instabilizadores, como sugere Passeti (1999), de modo a (in)habitualizar nosso modos de viver junto na urbe.

Devires instabilizadores que possibilitem produzir novas formas de habitar conjuntamente. Ocupar os espaços esquadrinhados - tomados ou não pelos signos da insegurança - configurando-os pela habitação e uso em outros espaços: espaços maleáveis, talvez. Rose (1999) critica a concepção de Lefebvre, para quem o espaço abstrato surge sob o desmoronamento da experiência vivida vencida por conceitos e representações. Para Rose, os espaços governados (representados e esquadrinhados) não são fabricados de modo contrário à experiência, mas tornam outros tipos de experiência e modos de percepção possíveis. Assim, a proposta que nos cabe é abrir estes espaços, de modo a permitir, dando lugar a novas construções (coletivas, comuns), outras experiências. Outras formas de ocupar o espaço de modo a produzir outras racionalidades do mesmo, de forma a abrir as delimitações impostas aos até então habitantes dessas esquadrinhações. Ocupar a cidade e seus espaços, permitindo que ela devenha. 
Tanto no rechaço efetuado por pessoas que se querem imunes a presença de uma população "maldita" quanto no furto de um guarda-chuva é possível (e provável) acompanhar os esquemas postos pela cidade habituada. Mas como sinaliza Do Eirado (1998), o habitual aponta mais ao problema do que a resposta. Talvez seja possível vê-lo como uma rua ou uma praça. Se o caminho de menor resistência é atravessar o mais rapidamente este espaço-questão e alcançar novamente um lugar(-comum) seguro, o problema também apresenta-se como "habitável". É possível ocupá-lo, fazer um novo uso do mesmo e reinventá-lo. Mais: habitá-lo e reinventá-lo, coletivamente.

A rua ocupada ou a praça ocupada não deixa de ser espaço de passagem, mas possui em si outro convite de uso, invoca uma outra sensibilidade para vivenciar o espaço, abrindo um novo campo de possibilidades. Tomemos, talvez, o medo previsto na cena da mudança do serviço e da não-aceitação dos moradores locais como um problema mais do que uma resposta. Habitar esse problema (ocupá-lo através da percepção daquilo que este conclama de inabitual) chama-o para um plano de comum onde possa-se produzir a cidade coletivamente, instabilizando a dicotomia entre privado (com seus signos de segurança que ainda assim, podem vislumbrar ataques e prever medo por trás de suas grades e câmeras) e público (colonizado como área de passagem e impessoalidade).

Tratamos assim de escapar das visibilidades dadas, colonizadoras das formas de ser que se tornam índice de significação (e, deste modo, das formas de habitar). Na ocupação conjunta, é possível construir-se novas visibilidades, visibilidades locais e contingentes aos encontros, cujas possibilidades não são abortadas pela necessidade de fixidez de sentidos e dos espaços. Resistir, assim, é habitar aquilo que se apresenta como brecha entre os espaços dados, entre-espaços que resistem (e se criam) em meio à cidade privatizante, de modo a fecundar estes interstícios e permiti-los crescer. Ultrapassar os muros afetivos, pervertendo-os. Produzir lugares maleáveis, onde o habitar possa ser inventado, onde o existir seja (in)habitual.

\section{Referências}

ALSAYYAD, N.; ROY, A. Modernidade medieval: cidadania e urbanismo na era global. Novos Estudos - CEBRAP, n. 85, p. 105-128, nov. 2009.

BARROS, M. E. B.; PIMENTEL, H. H. C. Políticas públicas e a construção do comum: interrogando práticas psi. Polis e Psique, Porto Alegre, v. 2, n. 2, p. 3-22, 2012.

BOURDIEU, P. Sociologia. São Paulo: Ática, 1983.

CALDEIRA, T. P. Cidade de muros: crime, segregação e cidadania em São Paulo. São Paulo: Editora 34, 2000.

DELEUZE, G.; GUATTARI, F. Micropolítica e segmentaridade. In: $\quad$ Mil platôs: capitalismo e esquizofrenia. Rio de Janeiro: Editora 34, 1996. v. 3, p. 76-106.

DO EIRADO, A. O hábito do ponto de vista ontológico e a produção da subjetividade. Revista do Departamento de Psicologia - UFF, Niterói, v. 10, n. 1, p. 4-8, 1998.

FOUCAULT, M. O que são as luzes?. In: MOTTA, M. B. (Org.). Arquelogia das Ciências e História dos Sistemas de
Pensamento. Rio de Janeiro, RJ: Forense Universitária, 2005. Coleção Ditos \& Escritos, v. 2, p. 335-351.

FOUCAULT, M. Nascimento da Biopolítica: curso dado no Collège de France (1978-1979). São Paulo: Martins Fontes, 2008a.

FOUCAULT, M. Segurança, território e população. São Paulo: Martins Fontes, 2008b.

GUATTARI, F; ROLNIK, S. Micropolitica: cartografias do desejo. Petrópolis, RJ: Vozes, 1996.

HARDT, M.; NEGRI, A. Império. Rio de Janeiro: Record, 2006.

HARDT, M.; NEGRI, A. Declaração: isto não é um manifesto. São Paulo: n-1 edições, 2014.

HARVEY, D. Os rebeldes na rua: O Partido de Wall Street encontra sua nêmesis. In: HARVEY, D. et al. Occupy: movimentos de protesto que tomaram as ruas. São Paulo: Boitempo, 2012. p. 57-64.

HARVEY, D. A liberdade da cidade. In: Cidades rebeldes: Passe Livre e as manifestações que tomaram as ruas do Brasil. São Paulo: Boitempo / Carta Maior, 2013a.

HARVEY, D. O neoliberalismo: história e implicações. São Paulo: Loyola, 2013b.

HUXLEY, A. Admirável mundo novo (1932). [S.1.]: Biblioteca Azul, 2004.

JORGE, M. A. S. A violência e o processo de mundialização. In: MOURÃO, J. C. (Org.). Clínica e política: subjetividade, direitos humanos e invenção de práticas clínicas. Rio de Janeiro: Abaquar, Grupo Tortura Nunca Mais - RJ, 2009. v. 2, p. 259-265.

LAGES, R. Direito à cidade. In: XIMENDES, A. M. C.; REIS, C.; OLIVEIRA, R. W. (Org.). Entre garantia de direitos $e$ práticas libertárias. Porto Alegre: CRPRS, 2013. p. 109-122.

LAZZARATO, M. As revoluções do capitalismo. Rio de Janeiro: Civilização Brasileira, 2006. Coleção Política no Império.

LEFEBVRE, H. O Direito à cidade. São Paulo: Moraes, 1991.

PASSETTI, E. Sociedade de controle e abolição da punição. São Paulo em Perspectiva, São Paulo, v. 13, n. 3, p. 56-66, jul./ set. 1999.

PASSETTI, E. O carcereiro que há em nós. In: XIMENDES, A. M. C.; REIS, C.; OLIVEIRA, R. W. (Org.). Entre garantia de direitos e práticas libertárias. Porto Alegre: CRPRS, 2013. p. 147-182.

RAZAC, O. Para uma sociologia do arame farpado. In: Outras Palavras, São Paulo, 23 set. 2013. Disponível em: $<$ http:// outraspalavras.net/outrasmidias/destaque-outras-midias/parauma-sociologia-do-arame-farpado/>. Acesso em: 20 nov. 2014.

ROSE, N. Powers of freedom: reframing political thought. Cambridge: Cambridge University Press, 1999.

Recebido em: 18 de março de 2015 Aceito em: 7 de julho de 2016 